$\begin{array}{cccc}\text { S sciendo } & \text { International Conference KNOWLEDGE-BASED ORGANIZATION } \\ \text { Vol. XXV } & \text { No } 3 & 2019\end{array}$

\title{
CONSIDERATIONS ON THE USE OF CERTAIN CERAMIC MATERIALS FOR INCREASING THE PROTECTION OF THE MILITARY
}

\author{
Florin ILIE, Nicolae MORO \\ “Nicolae Bălcescu” Land Forces Academy, Sibiu, Romania \\ ilieflorinv@yahoo.com, nicu.moro@yahoo.com
}

\begin{abstract}
This paper captures several aspects regarding the behavior of ceramic materials subjected to the impact with ballistic penetrators, focusing especially on the way they reduce the speed of the projectiles. Moreover, the numerical research associated with these models adds more knowledge in the field of the use of these ceramic materials for the protection of the military.
\end{abstract}

Keywords: individual protection, ballistic penetrators, ceramic materials, impac

\section{Conceptual Delimitation}

An accelerated development of the different types of ballistic penetrators can be seen lately in a world in which the major arms manufacturers are in a real competition to produce types of ammunition that are as performant as possible, capable of being more and more accurate at longer and longer distances, capable of carrying a multitude of combat components. As a counterpart, we can also notice the current and prospective concerns of the military specialists for the development of new types of means of protection both for civilians and especially for the military on the battlefield [2].

The study of the penetration/perforation of the individual protection structures by ballistic penetrators has always constituted a privileged field of study. Due to the perforation manner of various types of ammunition, with multiple capabilities and effects, especially in terms of muzzle velocity, mass, bullet shape and penetration power, the specialized literature is rather poor in providing information on the subject.

The aerodynamic form of the ballistic penetrators and the materials used in their design have been significantly improved. These are aspects that require the use of much more resistant materials for the protection of the military, and, at the same time, they must be lighter in order to maintain or even increase their mobility.

\section{Theoretical Considerations}

The development and the improvement of weapon systems and of individual protection capabilities have brought about a continuous dispute between bullets and projectiles on the one hand, and the means of protection, of armors, on the other. This binomial was created and developed by the needs of the current battlefield itself, by the desire to increase the attack and defense capabilities and especially by the improvement of the materials used in their construction, both in the offensive and the defensive versions [3]. 
We consider a bullet shaped ballistic penetrator, with the mass $m_{p}$ and the protection armor with the mass $m_{b}$. We also consider that the impact takes place after the normal on the surface of the armor and that the projectile has at the initial moment of impact the velocity $V_{i}$, and the force of inertia $F$, with which the projectile acts on the armor, is opposed only by the resistance force $R$ of the armor [6].
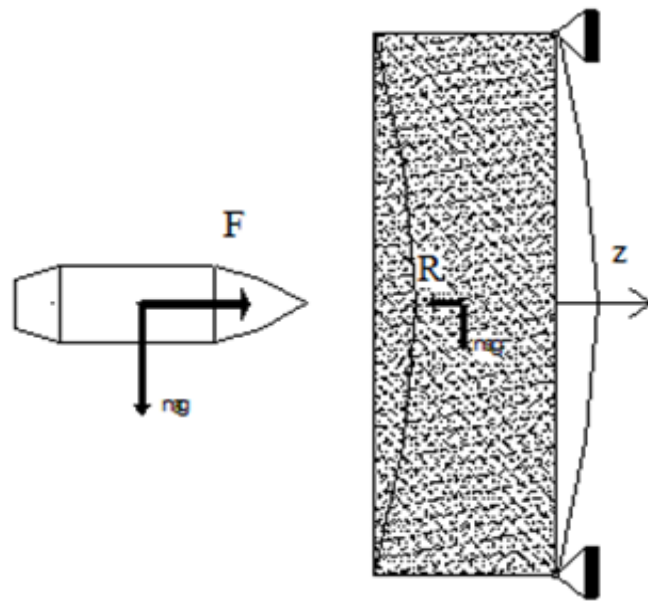

Figure 1: Modeling the impact [6]

Taking into account the force-balance principle, the bullet will move inside the armor according to the following equation of motion:

$$
\bar{F}+\bar{R}=0
$$

Its projection on the $z$-axis, normal to the surface of the armor, can be written as:

$$
\begin{aligned}
& m_{p} \frac{d V}{d t}+R(z, V)=0, \\
& \text { respectively: } \\
& m_{p} \frac{d^{2} z}{d t^{2}}+R(z, V)=0
\end{aligned}
$$

We consider $V=\frac{d z}{d t}$ and, if we eliminate the time in relation (2) we get the following relation [6]:

$$
\frac{1}{2} m_{p}\left(V_{i}^{2}-V_{r}^{2}\right)=\int_{0}^{h} R(z, V) d z,
$$

where $h$ is the thickness of the armor, and $V_{r-}$ is the remaining velocity of the bullet after having pierced the armor.

From this relationship we can, theoretically, deduce the depth $H_{\text {max }}$ reached by the projectile if it can not pass through the entire armor. For this, we considered the remaining velocity of the projectile to be zero, $V_{r}=0$, (the integral of the second member being solved for the 0 interval, $h=H_{\text {max }}$ ), or the remaining velocity of the projectile, $V_{r}$, in the case of the total perforation of the armor.

Another way in which equation (2) can be written is [5]:

$$
m_{p}\left(V_{i}-V_{r}\right)=\int_{0}^{T} R(z, V) d t,
$$

The relation from which we can determine the time $T_{V_{r}}$ after which the remaining velocity of the projectile reaches a determined value, $V_{r}$, or the time, $T$, of total armor perforation.

Knowing the variance of the resistance force $R(z, V)$ of the armor when the projectile advances through it, we have in relations (4) and (5) all thle elements we need to find out the manner in which the ballistic penetrator behaves at the impact with the armor [5].

This theoretical demarche must be followed by a practical study, by testing and bulletfiring for the entire range of impact velocities inside ballistic plates with imposed characteristics, which, unfortunately, requires a very high consumption of resources (especially financial resources) and can not be done in all the cases, which is why the calculations resulting from the theoretical methods can be accepted. 
3. Numerical Modeling and Experimental Testing of the Impact of the Ballistic Penetrator with the Protection System

Because of the very high differences in velocity, we can assume that the impact between the ballistic penetrator (the bullet in our case) and the armor structure is part of the category of mechanical collisions where the impulse force of the bullet has an approximately instantaneous increase (microseconds) up to a maximum value, followed by a accentuated deceleration towards zero, and the armor is at rest [4].

Because of the limitations of the level of the theoretical knowledge and of the technological development, it is necessary to accept and to implement simplifying assumptions as well as the use of empirical formulas and statistical data for the chosen simulation models, especially at the impact at high velocities between the ballistic penetrator and the protection armor. The extremely complex mathematical process generated by the phenomenon of the impact between the bullet and the armor can be solved by means of AUTODYN [1] by using finite element techniques, finite volumes, or techniques without a node network, and the methodology of the solution is given by an explicit algorithm of time integration. The differential equations generated by the impact at high velocities are solved through a set of algebraic equations obtained by digitization techniques. The principle of the method is briefly shown in Figure 2, in which, using the data known for the time step $t_{i}$, the solutions for the time step $t_{i+1}$ can be calculated [8].

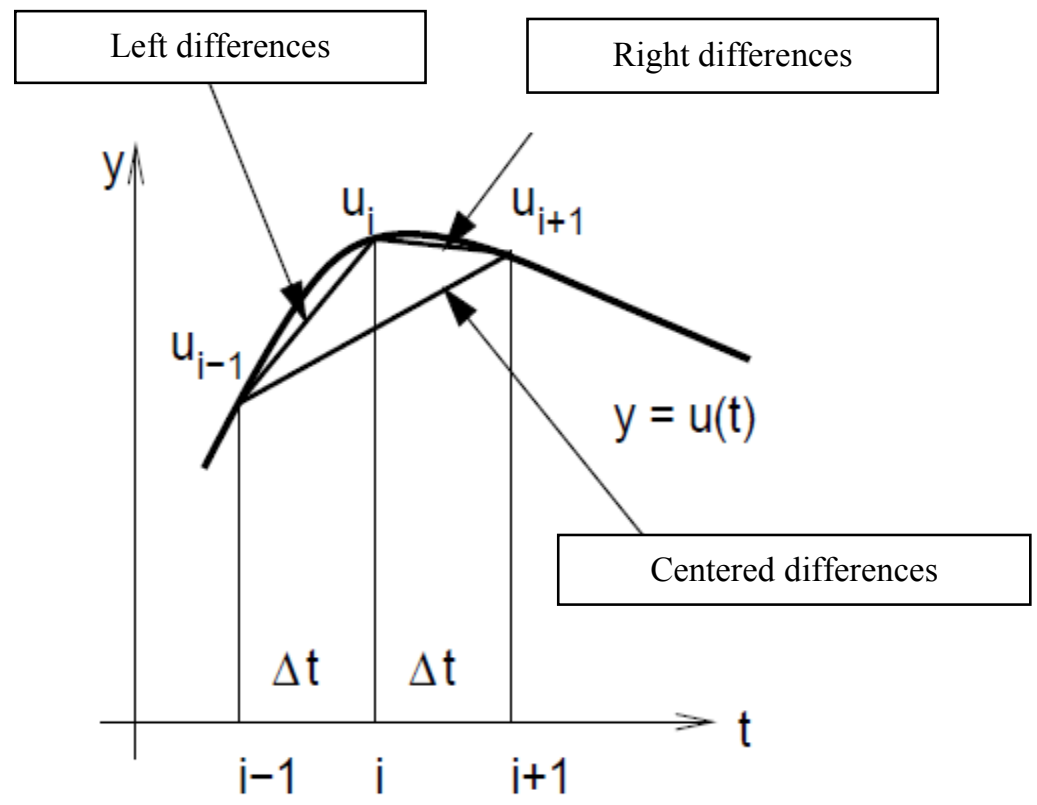

Figure 2: The principle of the AUTODYN methodi [1]

In order to achieve the simulation of the impact phenomenon, we used the SPH solver according to the recommendations of the specialized literature. This solver represents a Lagrange technique that has the advantage of accurately modeling the interfaces because it is flexible in terms of material patterns. The computational cycle used in the case of SPH by the AUTODYN solver, where the function is used in the calculation of the forces in the spatial derivatives of the stress and in the calculation of the deformation velocities starting from the spatial derivations of the velocity, is presented in Figure 3 [7]. 


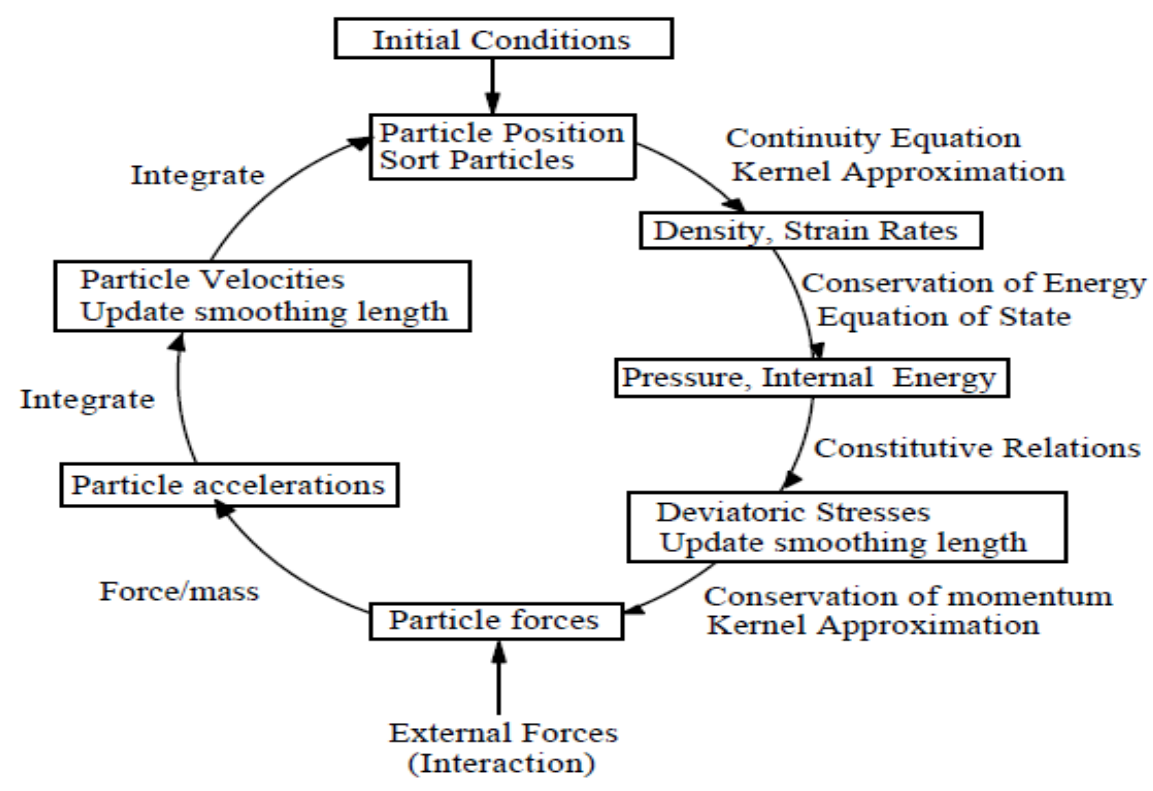

Figure 3: Calculation cycle SPH [7]

\section{Problem formulation}

In the numerical study, as well as in the shooting range tests, we used $7.62 \times 39 \mathrm{~mm}$ ammunition and the protective structure was made on an armor made of a $8 \mathrm{~mm}$ thick SINTOX ceramic plate glued to a blank $6 \mathrm{~mm}$ steel plate (Figure 4). We considered the velocity of the bullet at the impact with the armor of $800 \mathrm{~m} / \mathrm{s}$ and an angle of incidence of $90^{\circ}$.

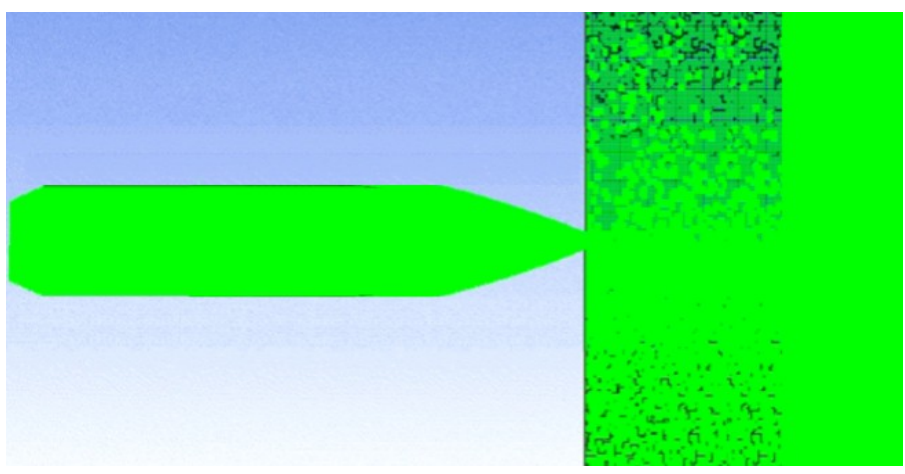

Figure 4: Modeling the initial moment of the impact

The utilized dynamic program of analysis offers data, images and graphs related to the strained state, the velocity field, the strain field, data regarding the kinetic energy, etc. (Figure 5). 


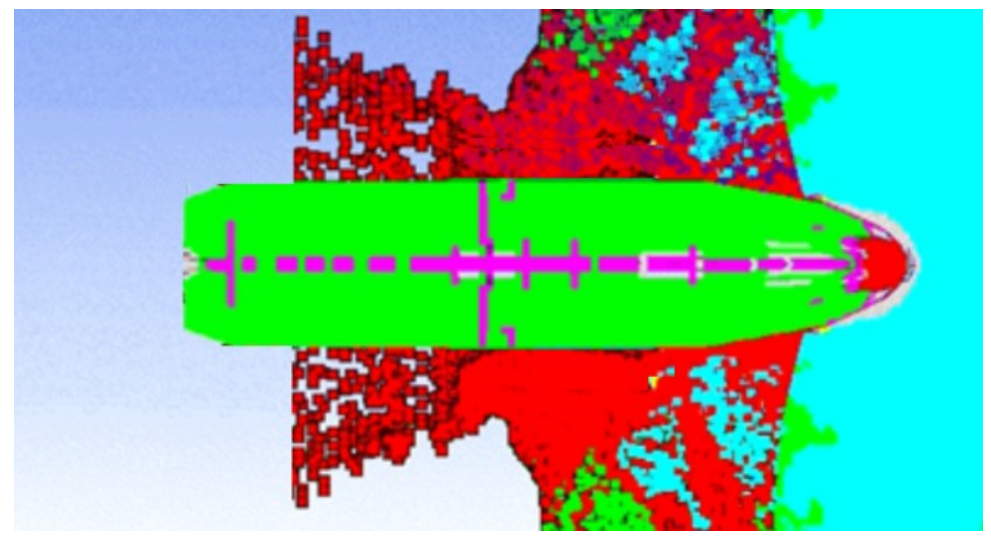

Figure 5: Modeling the initial moment of the impact

In order to correlate these numerical calculations with the real aspect of the phenomenon of the impact between the ballistic penetrator and the proposed armor structure, we also carried out an experimental study in the shooting range under the same conditions and with the same materials as in the case of mathematical modeling (Figure 6).

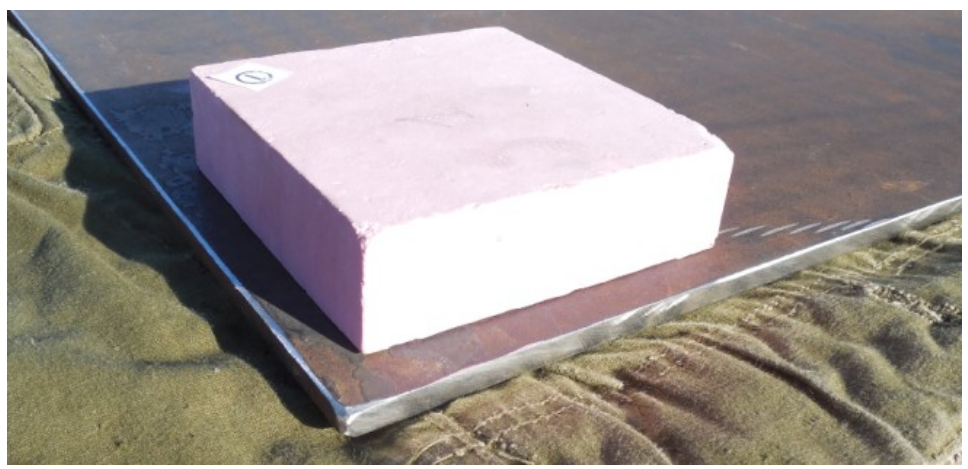

Figure 6: Armor configuration before firing

This is a very important aspect in the analysis and prediction of all the phenomena that may occur at the impact at high velocities between the bullet and the armor, for a description that is as objective as possible of the complex process that occurs at impact, as well as for the characterization of the behavior of the bullet when crossing the armor.

Following the shooting in the firing range, we noticed a typical scattering of the actual tests, and the explanation of this phenomenon is relatively simple, including the variation of the angle of impact due to the gyroscopic stabilization motion, the inconsistency of the material properties both for the perforating core of the bullet and for the ceramic plate, the effect of the adhesive layer, and perhaps it is also due to the effect of the bimetallic liner on the perforating core. Moreover, we could observe, in accordance with the results of the simulation and with the data from the specialized literature, that the ceramic plate was broken (Figure 7). 


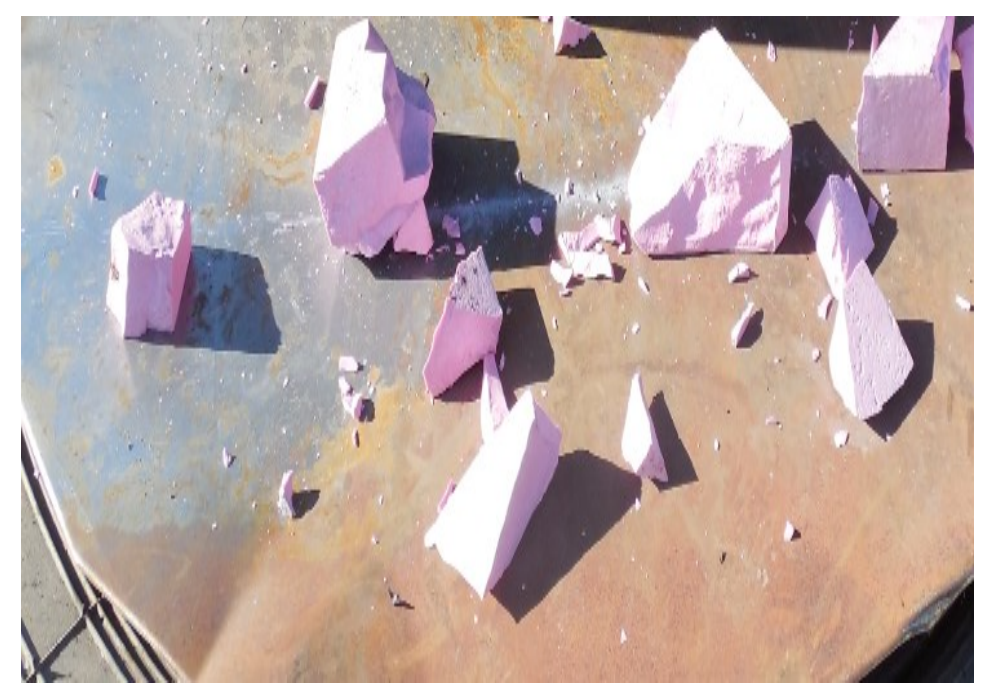

Figure 7: Ceramic protection system after shooting

Corroborating the results obtained from the numerical simulation with the observations resulting from the real aspect of the shooting, we can conclude that the breaking of the ceramic material is due primarily to the intensity of the shock generated by the impact between the bullet and the armor when the impact occurred at high speeds and in an area of the plate with good mechanical properties.

\section{Conclusions}

The phenomenon of the impact between a high velocity ballistic penetrator and a ballistic protection structure is a very complex phenomenon that is essentially reduced to the study of the effect of the projectile on the target. Therefore, in this paper, we considered useful to approach and detail the main theoretical, experimental and numerical simulation aspects of the impact phenomenon at high speeds. We also wanted to bring more insight into the solving of the difficult and complex problem of armor perforation with kinetic projectiles by underlying a wellrounded numerical modeling and validating it through experimental data obtained from real shootings. By comparing the results obtained in the firing range with the ones calculated by numerical modeling, we noticed that the errors between the two types of data do not differ by more than $10 \%$. This percentage enables us to consider that we fall within the permissible technical error limit and we can assume that the mathematical analysis of the impact phenomenon can become an indispensable calculation tool in the designing of modern munitions on the one hand and, on the other hand, in increasing individual protection, especially that of the military, by using ceramic materials.

\section{References}

[1] Century Dynamics, Inc. AUTODYN. Interactive Non-Linear Dynamic Analysis Software, 1997.

[2] Gadzalov, N. D., Balistics, monogaphy, Veliko Tarnovo, NMU Publisher, 2006, p. 387, ISBN - 978-954-753-044-7.

[3] Gadzalov, N. D. and Krastev, K. I., The use of "force to force" shooting training systems in the "Future officers" training, Vasil Levski NMU Annual Scientific Conference, Veliko Tarnovo, NMU Publisher, 2009. 
[4] Ilie, F., Numeric Modelling and Experimental Research of the Projectile and Armour's Impact Phenomenon, The 16th International Scientific Conference Knowledge-Based Organization, Sibiu, 2010.

[5] Liu, G. R., Meshfree Methods, Mooving Beyond the Finite Element Method, (2 ${ }^{\text {nd }}$ Edition), CRC Press Taylor \& Francis Group, 2010, LLC, ISBN 978-1- 4200-8209.

[6] Năstăsescu, V. and Bârsan, Gh., Metoda particulelor libere în analiza numerică a mediilor continue, Bucureşti, Editura AGIR, 2015, ISBN 978-973-720-617-6.

[7] Năstăsescu, V. and Bârsan, Gh., Metoda SPH (Smoothed Particle Hydrodynamics), Sibiu, Editura Academiei Forțelor Terestre "Nicolae Bălcescu", 2012, ISBN 978-973153-130-4.

[8] Năstăsescu, V. and Iliescu, N., Numerical Simulation of the Impact Problems by SPH Method, Proceedings of $I V^{\text {th }}$ National Conference The Academic Days of Academy of Technical Science, Vol. 1, pp. 193-198, Romania, Iasi, 19-20 November 2009, AGIR Publishing House, ISSN: 2066-6586. 